\title{
Effects of Stress and Hope on Happiness of Workers: The Moderating Mediation Model of Growth Mindset
}

\author{
Chang-Seek Lee, Hye-Jeong Gu
}

\begin{abstract}
The purpose of this study was to analyze the moderated mediation effects of growth mindset on the effects of stress and hope on the happiness of the employees, and to find ways to improve the happiness from the stress of the workers. SPSS PC + Win. 23 and SPSS MACRO process 3.1. were used for the completion of the data analysis. The main statistical techniques were noted as frequency analysis, reliability analysis, correlation analysis, and moderated mediation effect analysis. In this case, the effect analysis verification used bootstrap, with 5,000 samples of sub-trap and $95 \%$ confidence interval. The resulting research findings are as follows. First, Stress has negative correlation with growth mindset, hope and happiness. It is noted that growth mindset has a positive correlation with hope and happiness. Second, the moderated mediation effect of growth mindset on the pass from stress to hope and to happiness was verified.

These results will contribute to reducing stress and improving happiness of employees who suffered from job stress by applying the growth mindset to them.
\end{abstract}

Keywords : Stress, Hope, Growth mindest, Happiness, Moderated mediation effect

\section{INTRODUCTION}

Some people believe historically that humans constantly consult each other and scientists regarding finding the answers to the meaning and purpose of life. Humans are pondering what is good life and how to live their best lives, and the anxiety about this dichotomy continues from ancient philosophy to the present. It is known that Aristotle said that human beings live to be happy, and life that pursues happiness is a good life [1]. In other words, human behavior is goal-oriented, and ultimately the ultimate goal is goodness, which is defined as happiness in his theory regarding Nikomachos ethics. Aristotle also said that happiness is the meaning and purpose of life, and the goal and reason of human existence [2]. Therefore, there is an Eudaimonic View in the regard of human happiness that can be explored and related to human behavior..

The self-fulfilling viewpoint sees happiness as a process of self-realization by fully utilizing human potentialities such as talent, personality, and value, and aims at pursuit of desirable life rather than only the pursuit of obtaining sensuous

Revised Manuscript Received on July 22, 2019.

Chang Seek Lee, Dept. of Health, Counseling and Welfare, Hanseo University, 31962, Republic of Korea. Email: lee1246@hanmail.net

Hye-Jeong Gu, Dept. of Lifelong Education, Hanseo University, Seosan, Korea, Email: goobuki@ hanmail.net pleasure. In other words, we can discover happiness through the manifestation of a reviewed or found true self [3].

An ancient Western philosophy based on Aristotle viewed happiness from a self-fulfilling point of view. What begins with human self-realization in relation to what is good life, what life is worth, happiness beyond pleasure, which means that human prosperity and human infinity possibilities can be unfolded by a review of this definition of happiness during ancient times [4].

Just as the Greek happiness Eudaimonia means "a good life," healthy happiness is not only a joyful or satisfying level, but also a source of restoration or a foundation for further growth when faced with an adversity [1]. In fact, the various activities and institutions such as food, clothing, shelter, politics, economy, society, culture, and education that human beings enjoy today, are the result of efforts to pursue human happiness. The human desire to be happier has achieved today's material abundance and socio-cultural development in a general sense. As a result, however, these riches and civilizations did not make people happy overall in a modern perspective of the use of the concept.

Through the processes arising from the incongruity between human and environment (work), the origin of stress came into being. Stress comes from a Latin word and includes the meaning of 'tightness,' and it was named 'stress' in the 14th century where it was settled into one term. At this time, the meaning of stress has already been used to mean mental pain such as adversity, pain, and difficulty. By the 17th century, it was used to express pressure, physical tension, and anguish of the human mind and body. It was used in the 18th and 19th centuries to refer to mental and personal organisms. It was later introduced to the medical world from the late 19th century to the 20th century. At this time, we began to be interested in mental and physical health caused by stress, and research on the effect of stress on health began [5].

Stress, on the other hand, refers to the stressful situation and the pressure, frustration, conflict and anxiety experienced in such situations, emotions, and physical reactions by an individual, and it is difficult for the physical and mental condition as it is perceived as a negative condition to humans [6].

From the days when humans lived in caves as primitive people, the stress from the struggle for survival or the escape reaction started, and stress became an inevitable condition for human survival [5]. 
Walter Cannon [7] used the term "homeostasis" as the concept of stress for survival, and defined it as a process in which the internal environment is regulated in response to the external environment, in order to maintain proper body function. In other words, stress is not only bad, but it can have a good effect on an individual if the individual can maintain and regulate stress at a moderate level. Stress is not only not then considered bad as an effect on humans, but it also gives vitality to life because it induces tension by moderate stress [1].

On the other hand, Erikson[8] defines hope as a belief and trust that wishes can be achieved as a component of a healthy cognitive development of an individual. This is the power that comes when we balance the first step of psychosocial development, basic trust and distrust. In addition, Stotland [9] regarded hope as a concept that includes motivation and possibility, and considered it as a possible variable in a single dimension including perception of achieving the goal, but it could not be developed as a scientific tool. Breznits [10] proposed a working of hoping through a cognitive view of hopes related to transient thinking and cognitive status as seen in individuals. Furthermore, Nowotny [11] defined this idea as a multidimensional dynamic attribute that includes constructs such as wishes for future, active and active participation, intrinsic motivation, trust, feasibility, desire to relate to others or superior, enthusiasm, personal expectations of important values. Averill et al. emphasize the emotional aspects of hopes and defined that because hope is difficult to control, it is a passive approach rather than a behavior, and it has characteristics that can synchronize actions in the same way as other emotions [12].

Snyder et al. emphasize the understanding of cognitive processes of hope and suggests more multidimensional constructs. When defining hope, one should not overlook the instrumental aspects needed to pursue a goal, but also consider the cognitive appraisal of individuals in goal-directed activities. Based on this rationale, the researchers propose two interrelated components of hope as a goal-directed framework. In the hope theory, hope is defined as positive motivation based on close interaction between agency thinking, which means goal-directed energy, and pathways thinking, which is a concrete plan for achieving the goal [13]. In addition, Snyder [14] perceives human beings as being on an endless pursuit of goals, and always seeking to find an endeavor to achieve them. Snyder defines the hope as a traits or disposition that has the energy to achieve the goal, and attains the goal through the continual following of a concrete path working towards those goals. In other words, the goal is the energy that sustains human mental behavior and provides a cognitive factor to settle hope [15].

On the other hand, the theory of self-based theory is that people perceive mainly psychological characteristics in relation to others, and the surrounding environment, and are provided with an interpretive framework that allows these individuals to grasp and find a way to understand themselves internally [16]. On the basis of this theoretical basis, Bandura et al. [17] distinguished mindset by the entity theory that intelligence is fixed and by incremental theory that intelligence is changed by effort, centered on possibility of change of intelligence. Since then, Dweck [18] has developed the entity theory as fixed mindset, and the incremental theory as growth mindset, which is now a theory that is widely used and accepted in related academic circles. The two types of mindsets described above appear to vary according to the region, and even a single region is known to not be mutually exclusive. However, it is a general view that one of growth mindset and fixed mindset should be regarded as one dimension in which one tendency is shown to be superior [19]. On the other hand, the biggest difference between the growth mindset and the fixed mindset is the attitude toward that attitude and perception of failure. If the set of fixed minds is strong, a person will give up the challenge because the person is afraid of the failure itself, and will try only the area in which that the person is familiar. On the other hand, if a person has growth mindset, the individual also considers failure itself as a challenge, learning from such failures, and growing with new attempts [20]. The empirical study was mainly based on the differences in academic achievement of various groups of students. The students with higher growth mindset were more likely to achieve higher academic achievement in the mid-to long-term [21]. Thus, the self-directed learning attitude, which is an important predictor of academic achievement, is positively influenced by the growth mindset.

In conclusion, hope is a positive motivation to achieve successful outcomes. Therefore, it can be defined as all the perceptions that an individual can find ways to achieve personal goals, and use and implement methods and plans that are found to achieve goals. These hopes have been reported to be related to other variables in various domains. For example, it is shown that the hopes of mothers affected their children's happiness [22]. For a study of rural youth, agency thinking and pathways thinking were positively correlated with emotional well-being and behavioral control of psychological well-being [23]. In addition, there was a positive correlation between the incidence of a mother's hope and the infant's well-being, as shown in a review of mother-child studies. In the study on female marriage immigrants, hope was positively correlated with positive welfare and negatively correlated with negative welfare [24]. Based on the previous studies, it is expected that hopes will play a moderated mediation role in the results of these studies, and the research on these variables will also be meaningful.

Therefore, the purpose of this study was to analyze the moderated mediation effects of growth mindset on the mediating effects of hope, in the relationship between stress and happiness of the employees, and to find ways to improve the happiness from the identified stress. In order to achieve this goal, the following research questions were set up. First, what is the correlation between the main variables? Second, does growth mindset moderate the mediating effect of hope in the relationship between stress and happiness? 


\section{RESEARCH METHOD}

\section{A. Research Model}

In order to attain the purposes of the study research model in which growth mindset moderates the mediating effect of hope, in the relationship between stress and happiness was set as noted in the Figure 1.

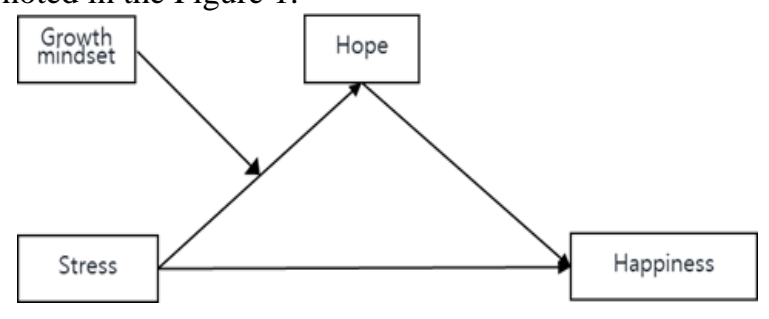

Figure 1: Research model

\section{B. Research Subject and date collection methods}

The research subjects were randomly sampled from three cities and counties in Chungcheongnam-do, and then there were taken samples from three groups of public officials, construction companies, and general industries in that location. The questionnaire that was distributed was collected by the researcher directly by visiting the institution or by postal mail, explaining to the subject the purpose of the survey, and then collecting the questionnaire immediately after the questionnaire was finished to minimize the loss of unfinished questionnaires.

\section{Measuring variables and measuring tools}

\section{- Stress}

In this study, we used the job stress scale developed by Parker and DeCotiis [25] to measure stress. The scale consists of 13 items and each item consists of 5-point Likert scale from 'not at all' (1 point) to 'very agree' (5 points). The higher the score, the higher the stress. In this study, the reliability coefficient of stress, Cronbach's alpha, was .839.

- Hope

We used the hope scale developed by Snyder et al. [13] and used by Choi et al.[26]. This scale consists of a total of 8 items, which is a measure of hopes of individuals as being individual characteristics for the basis of the study. Among them, 4 items for pathway thinking and 4 items for agency thinking were identified and measured. The item was rated on the 5-point Likert scale, from "not at all=1" to "very agree=5." The higher the score, the higher the hope. In this study, the reliability coefficient of hope, Cronbach's alpha, was .903 .

- Growth mindset

Growth mindset is a tool for measuring whether an individual is closer to a fixed mindset or a growth mindset. This brings us to understand that Dweck et al. [27] used the growth mindset Stereotype Scale, which is subdivided into intelligence and personality traits. The total number of questions is 8 , and for each sub-factor, the growth mindset for the intelligence consists of 2 positive and 2 negative questions, and the set of growth mindset about personality consists of 4 positive items. The range of the items was measured on a 5 -point Likert scale ranging from 1 point to 5 points. The higher the score, the higher the score of growth mindset. In this case, the Cronbach's alpha of this scale was .797.

\section{- Happiness}

Happiness was measured by using the happiness scale of Lyubomirsky and Lepper [28]. This scale is composed of 5 items such as 'I am a happy person when I consider all things' and 'I can not live as happy as I want,' to find out the happiness of the current life of the respondent himself. It is composed of utilizing a 6-points Likert scale from 'not at all' (1 point) to 'very agree' ( 6 points). The higher the score, the higher the happiness was measured in this case. In this study, the reliability coefficient of happiness, Cronbach's alpha, was .872 ,

\section{Data Analysis}

In this study, data analysis was performed using SPSS PC + Win. 23.0 and SPSS PROCESS macro. Frequency analysis, Cronbach's $\alpha$, and Pearson's correlation analysis were used by using SPSS PC + Win. 23.0. In addition, we used SPSS PROCESS macro to verify the moderated mediation effect and set the number of bootstrap samples to 5,000 and the confidence interval to $95 \%$.

\section{RESULTS AND DISCUSSION}

\section{A. Correlation And Descriptive Statistics}

In these terms, Pearson's correlation analysis results are presented in Table 1. All correlation coefficient between variables showed a significant correlation in this case. For example, stress has negative correlation with growth mindset, hope and happiness, and the incidence of growth mindset has a positive correlation with hope and happiness.

Descriptive statistics showed that the stress was lower than the median of 3, but the growth mindset, hope and happiness were higher than the median. Especially happiness showed the highest average.

These results are consistent with the study result that high-hoped children have higher levels of happiness than low-hoped children [29], and that people with high hopes maintain positive status, are active in stress management, and are more socially adaptive [30].

Table 1: Results of correlation analysis and descriptive statistics

\begin{tabular}{l|c|c|c|c|c|c}
\hline & 1 & 2 & 3 & 4 & $\mathrm{M}$ & SD \\
\hline 1. Stress & 1 & & & & 2.6354 & 0.61527 \\
\hline 2.Growth mindset & $-.245^{* *}$ & 1 & & & 3.3335 & 0.61394 \\
\hline 3. Hope & $-.251^{* *}$ & $.257^{* *}$ & 1 & & 3.5564 & 0.59465 \\
\hline 4. Happiness & $-.359^{* *}$ & $.295^{* *}$ & $.574^{* *}$ & 1 & 3.7139 & 0.65985 \\
\hline$* * p<0.1$
\end{tabular}

\section{B. Moderates mediation effect of growth mindset}

We use the Model 7 of PROCESS macro for SPSS proposed by Hayes [31] to determine whether growth mindset moderates the mediating effects of hope on the relationship between the measured variables of job stress and happiness. The number of the applicable bootstrap sample was set at 5,000 and the confidence interval is set at $95 \%$. The analysis results are shown in Figure 2 and Table 2.

First, in the mediating model, stress has a significant effect on hope, and it was determined in this study that the growth mindset also has a significant 
effect on hope. The interaction effect between stress and growth mindset was -.1509 ( $\mathrm{p}<.05)$, which means that the moderating effect is significant.

The conditional effects of stress were significant only at $\mathrm{M}$ and $\mathrm{M}+\mathrm{SD}$ of growth mindset and not significant at M-SD value of growth mindset. In other words, the conditional effect of stress was significant when growth mindset is more than the average. In Figure 2, as the stress increases, the hopes decrease, but such a tendency is lower in the high group of the growth mindset than in the low group of growth mindset.

Second, for the mediating effects, stress had been noted with a significant negative effect on hope $(-.2024, p<.001)$, and hope had a significant effect on happiness (.5741, $\mathrm{p}$ $<.001)$. Therefore, it was shown that the mediating effect of hope was verified.

These results show that the higher the job stress, the lower the hopes, the higher the psychological exhaustion, and the higher the hopes, and the lower the psychological exhaustion[32]. It shows that people with high hopes can lower psychological exhaustion even when the stress from lack of opportunity is high. Hopeful people are active in monitoring their own stress management [33], and may perceive that even if obstacles are encountered in fulfilling their goals, life is a challenge, and they think about social support networks and ask for help [14]. Therefore, the results of this study are similar to those of the above studies.

Third, for moderated mediation effect of growth mindset, the conditioned indirect effect was significant when the growth mindset was noted in the middle or high group. On the other hand, it was not significant in the lower growth mindset group. Thus, there was a moderated mediation effect of growth mindset in the path from stress to happiness via hope.

These results are in line with the studies that the growth mindset of adults moderated the mediating effects of authentic leadership on the relationship between hope and organizational effectiveness [34], and that the growth mindset of middle school students moderated the mediating effect of self-esteem on the relationship between parental abuse and school violence [35]. Therefore, it is necessary to improve the growth mindset in order to relieve the stress of the worker and to improve the happiness of the individual workers, and furthermore, it is necessary to develop a program to promote the growth mindset.

Table 2: Moderated mediation effect of growth mindset

\begin{tabular}{|c|c|c|c|c|c|c|}
\hline Variables & $\begin{array}{c}\text { Coeff } \\
\text { ect }\end{array}$ & SE & $\mathrm{t}$ value & $\mathrm{p}$ & LLCI $^{*}$ & $\mathrm{ULCI}^{* *}$ \\
\hline \multicolumn{7}{|c|}{ Mediating variables model (DV: Hope) } \\
\hline constant & $\begin{array}{c}3.546 \\
9 \\
\end{array}$ & .0314 & $\begin{array}{c}112.94 \\
69\end{array}$ & .0000 & 3.4851 & 3.6087 \\
\hline Stress & $\begin{array}{c}-.202 \\
4 \\
\end{array}$ & .0516 & -3.9243 & .0001 & -.3038 & -.1009 \\
\hline $\begin{array}{l}\text { Growth } \\
\text { mindset }\end{array}$ & .1741 & .0525 & 3.3187 & .0010 & .0709 & .2773 \\
\hline $\begin{array}{l}\text { Stress x } \\
\text { Growth } \\
\text { mindset }\end{array}$ & $\begin{array}{c}-.150 \\
9\end{array}$ & .0765 & -1.9739 & .0492 & -.3014 & -.0005 \\
\hline
\end{tabular}

Test(s) of highest order unconditional interaction(s):

\begin{tabular}{c|c|c|c}
\hline $\begin{array}{c}\text { Stress } \mathrm{x} \\
\text { Growth }\end{array}$ & $R^{2}$ & $\mathrm{~F}$ & $\mathrm{p}$ \\
\hline
\end{tabular}

\begin{tabular}{|c|c|c|c|c|c|c|}
\hline mindset & & .0104 & \multicolumn{2}{|c|}{3.8963} & \multicolumn{2}{|c|}{.0492} \\
\hline \multicolumn{7}{|c|}{ Conditional effects of the stress at values of growth mindset } \\
\hline $\begin{array}{l}\text { Growth } \\
\text { mindset }\end{array}$ & $\begin{array}{c}\text { Effe } \\
\text { ct }\end{array}$ & se & $\mathrm{t}$ & $\mathrm{p}$ & LLCI $^{*}$ & ULCI $^{* *}$ \\
\hline-.6128 & \begin{tabular}{|c|}
-.10 \\
99
\end{tabular} & .0673 & -1.6314 & .1038 & -.2423 & .0226 \\
\hline .0000 & \begin{tabular}{|c|}
-.20 \\
24
\end{tabular} & .0516 & -3.9243 & .0001 & -.3038 & -.1009 \\
\hline .6128 & \begin{tabular}{|c|}
-.29 \\
49
\end{tabular} & .0719 & -4.0986 & .0001 & -.4364 & -.1533 \\
\hline
\end{tabular}

Conditional effects of the stress at values of growth mindset

Growth Mindset Effect se $\quad$ t $\quad p \quad$ LLCI ULCI

\begin{tabular}{lcccc}
-1.7131 & .0562 & .1376 & .4086 & .6831 \\
-.2144 & .3268 & & & \\
\hline
\end{tabular}

\begin{tabular}{llllll}
\multicolumn{7}{c}{$:$} \\
-.5318 & -.1221 & .0635 & -1.9220 & .0555 & \\
-.2470 & .0029 & & & & \\
\hline-.5198 & -.1239 & .0630 & -1.9671 & .0500 & \\
-.2478 & .0000 & & & & \\
\hline-.3631 & -.1476 & .0569 & -2.5923 & .0100 & -.2595 \\
-.0356 & & & & & \\
\hline
\end{tabular}

\begin{tabular}{llllll}
\hline 1.6619 & -.4532 & .1403 & -3.2308 & .0014 & -.7291 \\
-.1773 & & & & & \\
\hline
\end{tabular}

Dependent variable model (DV: Happiness )

\begin{tabular}{|c|c|c|c|c|c|c|c|}
\hline Variables & $\begin{array}{c}\text { Coeff } \\
\text { ect }\end{array}$ & & SE & $\mathrm{t}$-value & $\mathrm{p}$ & LLCI $^{*}$ & ULCI $^{* *}$ \\
\hline Constant & $\begin{array}{c}1.668 \\
6\end{array}$ & & .1784 & 9.3528 & .0000 & 1.3177 & 2.0196 \\
\hline Stress & $\begin{array}{c}-.249 \\
0\end{array}$ & & .0478 & -5.2107 & .0000 & -.3430 & -.1550 \\
\hline Hope & .5741 & & .0495 & $\begin{array}{c}11.606 \\
8\end{array}$ & .0000 & .4768 & .6714 \\
\hline \multicolumn{8}{|c|}{$\begin{array}{l}\text { Conditional indirect effects of } \mathrm{X} \text { on } \mathrm{Y} \\
(\text { Stress } \rightarrow \text { Hope } \rightarrow \text { Happiness })\end{array}$} \\
\hline $\begin{array}{l}\text { Growth } \\
\text { mindset }\end{array}$ & & \multicolumn{2}{|l|}{ Effect } & Bootse & \multicolumn{2}{|c|}{ BootLLCI } & $\begin{array}{l}\text { BootUL } \\
\mathrm{CI}^{* *}\end{array}$ \\
\hline-.6128 & & \multicolumn{2}{|l|}{-.0631} & .0542 & \multicolumn{2}{|c|}{-.1662} & .0447 \\
\hline .0000 & & \multicolumn{2}{|l|}{-.1162} & .0404 & \multicolumn{2}{|c|}{-.1985} & -.0391 \\
\hline .6128 & & \multicolumn{2}{|l|}{-.1693} & .0556 & \multicolumn{2}{|c|}{-.2782} & -.0639 \\
\hline
\end{tabular}

${ }^{*} \mathrm{LLCI} \overline{\mathrm{CI}}$ boot The lower limit of the indirect effect within the $95 \%$ confidence interval

**ULCI=boot The upper limit of the indirect effect within the $95 \%$ confidence interval

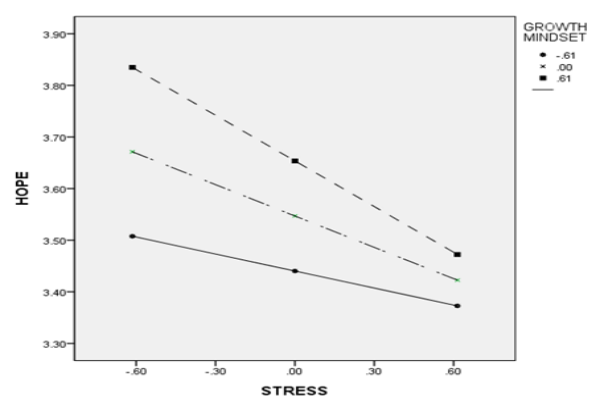

Figure 2: The moderating effect of growth mindset on the relationship between stress and hope 


\section{CONCLUSION}

The conclusions of the study are as follows.

First, all correlations between the identified variables showed a significant correlation in the study. It was shown that stress has negative correlation with growth mindset, hope and happiness. Conversely, it was noted that growth mindset has a positive correlation with hope and happiness.

Second, the conditioned indirect effect of growth mindset was significant when the growth mindset was seen or noted in the middle or high group. On the other hand, it was not significant in the lower growth mindset group as a result of the study parameters. Thus, there was a moderated mediation effect of growth mindset in the path from stress to happiness via the noted areas of hope from the participants.

Finally, based on the limitations of this study, the following suggestions for the follow-up study are as recommended follows. First, the subject of this study was collected from the several regions in Chungnam area. Therefore, it is difficult to extend the results of this study to the Korean nation in a general sense. In the future, sampling needs to be done nationwide, and it is necessary to increase the possibility of generalization for subsequent studies. Second, in this study, it is necessary to develop a program applying hope and growth mindset to improve and measure the happiness of the worker.

Despite these limitations, this study has important implications for analyzing the conditional indirect effects of growth mindset on the pathway between job stress, hope and happiness of workers and employees.

\section{ACKNOWLEDGMENT}

This study was undertaken with the support of a research grant in 2019 from Hanseo University.

\section{REFERENCES}

1. H. J. Choi. A study on the constituents of worker's happiness: Focusing on development of measurement tools [master's thesis]. [Seoul]: Ewha Women University; 2016. Available from: http://www.riss.kr/search/detail/DetailView.do?p_mat_type=be54d9b8 bc7cdb09\&control_no=271e2d869a6cb935ffe0bdc3ef48d419

2. R. Crisp (Ed.). Aristotle: Nicomachean Ethics. Cambridge: Cambridge University Press; 2014.

3. S. R. Baumgardner, M. K. Crothers. Positive psychology. New Jersey: Pearson Education; 2009.

4. D. J. Disabato, F.R. Goodman, T. B. Kashdan, J. L. Short, A. Jarden Different types of well-being? A cross-cultural examination of hedonic and eudaimonic well-being. Psychological Assessment. 2016 May;28(5):471-482.

5. D. H. Lee. Worker stress analysis: Focused on large enterprises [master's thesis]. [Incheon]: Inha University; 2013. Available from: http://www.riss.kr/search/detail/DetailView.do?p_mat_type=be54d9b8 bc7cdb09\&control_no=c0c4012a99cadeefffe0bdc3ef48d419

6. J. G. Kim. The effect of high school students' social support and stress on internet addiction [master's thesis]. [Daejeon]: Daejeon University; 2005. Available http://www.riss.kr.libmeta.knou.ac.kr:8010/link?id=T9873422

7. W. B. Cannon. Bodily changes in pain, hunger, fear, and rage, ed2. Boston, CH Branford. 1953;39(2):20-36.

8. E. H. Erikson. Inner and outer space: Reflections on womanhood. Daedalus. 1964;93(2):582-606.

9. E. Stotland. The psychology of hope. San Francisco: Jossey-Bass Behavioral Science Series; 1969.

10. S. Breznitz. The effect of hope on coping with stress. In Dynamics of Stress Boston: Spring; 1986.

11. M. L. Nowotny. Assessment of hope in patients with cancer: Development of an instrument. In Oncology Nursing Forum. 1989 Jan; 16(1):57-61
12. J. R. Averill, G. Catlin, K. K. Chon. Rules of hope. New York: Springer Science \& Business Media; 1990.

13. C. R. Snyder, C. Harris, J. R. Anderson, S. A. Holleran, L. M. Irving, S. T. Sigmon, et al. The will and the ways: Development and validation of an individual-differences measure of hope. Journal of Personality and Social Psychology. 1991 Apr; 60(4):570-85.

14. C. R. Snyder. The psychology of hope: You can get there from here. New York: Free Press; 1994.

15. C. R. Snyder, S. C. Sympson, S. T. Michael, J. Cheavens. Optimism and hope constructs: Variants on a positive expectancy theme. Optimism and Pessimism: Implications for Theory, Research, and Pactice. Washington DC: American Psychological Association; 2001.

16. D. C. Molden, C. S. Dweck. Finding "Meaning" in psychology: A lay theories approach to self-regulation, social perception, and social development. American Psychologist. 2006;61(3):192-203.

17. S. K. Lee. A study on relationship between growth mindset, fixed mindset and grit of young adults: the mediating effects of resilience [master's dissertation]. [Seoul]: Ewha Woman's University; 2016 Available

from

http://www.riss.kr/search/detail/DetailView.do?p_mat_type=be54d9b8 bc7cdb09\&control_no=207d683906938408ffe0bdc3ef48d41

18. C. S. Dweck. Mindset: The new psychology of success. New York: Ballantine Books; 2006.

19. C. S. Dweck, C. Chiu, Y. Hong. Implicit theories and their role in judgments and reactions: A world from two perspectives. Psychological Inquiry. 1995;6(4):267-285.

20. J. S. Hyun, C. J. Park. Learnimg effects of divide-and-combine principles and state models on contradiction problem solving and growth mindest. Knowledge Management Rwview. 2013;14(4):19-46. DOI:10.15813/kmr.2013.14.4.002. Available from: http://www.riss.kr/search/detail/DetailView.do?p_mat_type=1a0202e3 7d52c72d\&control_no=1407b00a138766dcffe0bdc3ef48d419

21. S. J. Lee, T. S. Shin. The effects of mindsets on academic self-efficacy of high school students mediated by grit: Multi-group analysis according to whether the students gave up on mathematics or not. Asian Journal of Education. 2018 Mar;19(1):59-87. Available from http://www.riss.kr/search/detail/DetailView.do?p_mat_type=1a0202e3 7d52c72d\&control_no=2b4cf030e7d607374884a65323211ff0

22. C. S. Lee. The roles of hope and growth mindset in the relationship between mothers' parenting stress and children's well-being. Indian Journal of Science and Technology. 2016 Dec; 9(47):1-5. .DOI:10.17485.

23. C. S. Lee, Y. K. Hwang. A study on the variables influencing the academic procrastination of adolescents in rural areas. International Journal of Applied Engineering Research (IJAER). 2015 Oct;10(79):158-161.

24. J. Y. Park, C. S. Lee. Mediating effect of hope on the relationship between cultural adaptation stress and psychological welfare of female married immigrants. Digital Policy Research. 2012 Nov;10(11):665-672.

25. D. F. Parker, T. A. DeCotiis. Organizational determinants of job stress Organizational Behavior and Human Performance. 1983 Oct;32(2):160-177. Available from: https://doi.org/10.1016/0030-5073(83)90145-9

26. H. K. Lee, D. G. Lee, Y. H. Choi. Validation of the Korean version of Snyder`s dispositional hope scale. Korean Journal of Social and Personality Psychology. 2008 Feb;22(2):1-16.

27. C. S. Dweck. Mindset: The new psychology of success. Random House 2006.

28. S. Lyubomirsky, H. S. Lepper. A measure of subjective happiness: preliminary reliability and construct validation. Social indicators research. 1999 Nov; 46(2):137-55. DOI: 10.1023/A:1006824100041.

29. M. R. Kim. The effect of stress on happiness: Moderating effect of gratitude and hope [master's dissertation]. [Daegu]: Daegu Catholic University; 2014. Available from: http://www.riss.kr/search/detail/DetailView.do?p_mat_type=be54d9b8 bc7cdb09\&control_no=e6ae997a0c5cfbbbffe0bdc3ef48d419

30. C. R. Snyder, J. Cheavens, S. C. Sympson. Hope: An individual motive for social commerce. Group Dynamics: Theory, Research, and Practice. 1997; 1(2):7-118.

31. J. Hayes. The theory and practice of change management. Palgrave. London; 2018. 
32. J. Y. Song. The Relationship between job stress and psychological exhaustion of the first counselor: Moderating effects of hope [master's thesis]. [Bucheon]: Catholic University; 2013. Available from: http://www.riss.kr/search/detail/DetailView.do?p_mat_type=be54d9b8 bc7cdb09\&control_no=2393083f079ee9c5ffe0bdc3ef48d419

33. C. R. Snyder, K. M. Pulvers. Dr. Seuss, the coping machine, and "Oh, the Places You'll Go.” In C. R. Snyder (Ed.), Coping with stress: Effective people and processes. Oxford: Oxford University Press; 2001

34. C. S. Lee. Authentic leadership and organizational effectiveness: the roles of hope, grit, and growth mindset. International Journal of Pure and Applied Mathematics. 2018 Jan; 118(19):1439-1452.

35. Y. K. Hwang, C. S. Lee. Victimization of adolescents by parental abuse and school violence: A moderated mediation model of self-esteem and growth mindset. International Journal of Pure and Applied Mathematics. 2018 Feb;118(19):383-401.

\section{AUTHORS PROFILE}

Chang Seek Lee received Bachelor's and Master's degree in lifelong education from Seoul National University in Korea and Ph.D. in lifelong education from University of the Philippines in the Philippines in 1991. $\mathrm{He}$ is chairman of health,, counseling and welfare department of Hanseo University, South Korea and Head of Multicultural Education and Welfare Institute of Hanseo University. His primary research interests are program development, lifelong education and multicultural education.

Hye-Jeong Gu is taking a $\mathrm{Ph} . \mathrm{D}$ programs in lifelong education department of Hanseo University. Her major concerns are lifelong education and counseling psychology. 